\section{Shortening the Production Cycle of Clematis}

\author{
Uttara C. Samarakoon and James E. Faust \\ Plant and Environmental Sciences Department, Clemson University, E143 \\ Poole Agriculture Center, Clemson, SC 29634
}

Additional index words. bulking, cold treatment, ethephon, forcing, photoperiod, vernalization

\begin{abstract}
Clematis (Clematis $\times$ hybrida) is among the flowering plants well-recognized by the retail consumer; however, production has not traditionally fit into standard greenhouse production systems. One reason is the relatively long 2-year production cycle from propagation to flowering. Four experiments were conducted with clematis 'H.F. Young' to understand the factors that influence shoot development and flowering of clematis so that strategies could be developed for bulking, providing a cold treatment, and flowering the plants with a shortened production time. The first experiment showed an increase in shoot and flower numbers and a decrease in time to flower as the duration of cold treatment increased from 0 to 9 weeks and the photoperiod increased from 9 to 16 hours. The second experiment resulted in greater shoot and flower numbers when plants were forced at $21^{\circ} \mathrm{C}$ as compared with $27^{\circ} \mathrm{C}$. The third experiment showed that the application of ethephon ( 500 or $1000 \mathrm{mg} \cdot \mathrm{L}^{-1}$ ) during bulking increased shoot formation (branching) as compared with the control or $500 \mathrm{mg} \cdot \mathrm{L}^{-1}$ benzylaminopurine treatments. The fourth experiment showed that applications of $500 \mathrm{mg} \cdot \mathrm{L}^{-1}$ ethephon along with a 16-hour photoperiod during the bulking period improved shoot number and flowering of the finished crop. The combined results provide guidelines for producing a well-branched, flowering clematis crop within 1 year from the start of propagation to the time of the first open flower.
\end{abstract}

Clematis is an ornamental perennial vine that is among the most well-recognized ornamental plants in the retail market; however, production has not traditionally fit into the greenhouse production cycle for vegetatively propagated, herbaceous perennial crops. The major reason is that the production cycle from propagation to market takes 2 years. The conventional production schedule for a temperate climate zone is described as follows. Propagation from one-node or twonode stem cuttings takes an average of 10 weeks during the summer. Then, rooted liners are transplanted to larger containers and grown for the remainder of the summer. The vining shoots may be trimmed once or twice to minimize the entanglement of the plant canopy during this first bulking period.

Received for publication 19 Aug. 2020. Accepted for publication 2 Oct. 2020.

Published online 30 October 2020.

We thank Kelly Lewis, Alexandra Carver, Misty Sheely, Christopher Cortina, Timothy Knauer, Jordan Baylor, and Trey Tempel for their technical assistance.

Technical Contribution No. 6903 of the Clemson University Experiment Station. This material is based upon work supported by NIFA/USDA, under project number SC-1700585.

Current address for U.C.S.: The Ohio State University Agricultural Technical Institute, 1328 Dover Road, Wooster, OH 44691

J.E.F. is the corresponding author. E-mail: jfaust@ clemson.edu.

This is an open access article distributed under the CC BY-NC-ND license (https://creativecommons. org/licenses/by-nc-nd/4.0/). before the cold treatment to promote shoot development after the cold treatment, (i.e., during forcing).

Shoot emergence, development, and flowering in clematis may be promoted by the cold treatment, photoperiod, and temperatures in the forcing environment; however, as noted for other herbaceous perennials, plants must be physiologically capable of perceiving the cold treatment (Dole, 2003). Most of the herbaceous perennials in temperate regions use buds produced during the previous growing season for the shoot production of the current season (Vesk and Westoby, 2004). Environmental factors before cold treatment, such as transferring plants from long days to short days, promote bud formation from underground storage structures in some herbaceous perennials as compared to continuous growth under long days (Samarakoon et al., 2015). This response is potentially due to short days being favorable for the partitioning of photoassimilates from aboveground shoots to underground storage organs (Shillo and Halevy, 1981). Therefore, we hypothesized that the photoperiod during the bulking period could have an impact on branching and flowering after the cold treatment.

Shoot emergence, development, and flowering occur in some temperate perennials only when the requirements for cold temperatures have been satisfied (i.e., vernalization and/or breaking of endodormancy) (Iversen and Weiler, 1994). Inadequate accumulation of chilling units can result in delayed or uneven shoot emergence, reduced budbreak, and slow or weak shoot growth (Lang et al., 1987). Therefore, the duration of the cold treatment required for vernalization and/or breaking dormancy can improve shoot formation and flowering in clematis. Because of the lack of information related to the cold requirement for clematis, $5{ }^{\circ} \mathrm{C}$ was used to provide the cold treatments during our experiments because this temperature is recommended for initial studies with herbaceous perennials of temperate origins (Dole, 2003).

Following the cold treatment, the growing environment during forcing can impact shoot development and flowering in perennials. Research reports of the photoperiod and temperature in the growing environment for clematis are limited; however, data have been presented for several herbaceous perennials (Armitage and Garner, 1999). For Oenothera fruticosa (Clough et al., 2001) and Anchusa capensis (Armitage and Garner, 1999), time to flower decreased with the increased photoperiod. Reduced flowering time in response to increased temperature during forcing was noted in Lavendula angustifolia 'Munstead' (Whitman et al., 1996) and Companula carpatica 'Blue Clips' (Whitman et al., 1997). Therefore, identifying the response to the photoperiod and temperature in the forcing environment is essential to reduce the production schedule for clematis while achieving adequate flowering.

The objectives of this project were as follows: to reduce the conventional 
production schedule for clematis by providing the following: 1) the appropriate photoperiod and plant growth regulator treatments during the bulking period such that just one bulking period was needed to achieve adequate branching during forcing, 2) one dormancy (cold) period, 3) the optimal duration of cold to achieve adequate flowering, and 4) the response to the photoperiod and temperature during the forcing period to achieve adequate flower numbers.

\section{Materials and Methods}

General procedures. Clematis 'H.F. Young' plants were grown in Clemson, SC (lat. $35^{\circ} \mathrm{N}$, long. $83^{\circ} \mathrm{W}$ ) in a glass greenhouse with an environment controlled by a climate-control computer (Argus Control Environmental Systems, White Rock, BC, Canada). Heating and ventilation set points during the day and night were 22 and $27{ }^{\circ} \mathrm{C}$, respectively, unless otherwise noted. Plants were shaded with retractable curtains (55\% photosynthetic photon flux reduction) when the photosynthetic photon flux density $(P P F D)$ measured outside the greenhouse exceeded $968 \mu \mathrm{mol} \cdot \mathrm{m}^{-2} \cdot \mathrm{s}^{-1}$. A peat-based growing medium (Fafard 3B; Conrad Fafard, Inc., Agawam, MA) was used for all experiments. A constant liquid fertigation schedule was used with Peter's Excel (15N-2.2P$12.5 \mathrm{~K}-5 \mathrm{Ca}-2 \mathrm{Mg}$; Scotts-Sierra, Marysville, $\mathrm{OH}$ ) to provide $200 \mathrm{mg} \cdot \mathrm{L}^{-1} \mathrm{~N}$ at each irrigation.

Four experiments were conducted. The effects of cold treatment duration followed by those of the photoperiod and temperature in the forcing environment were determined during Expts. 1 and 2 so that the best treatments for flowering could be provided to the plants following the growing phase in the bulking period during Expts. 3 and 4.

Expt. 1: Effects of the duration of cold treatment and photoperiod on the growth and flowering of clematis. One-hundred sixty 15month-old (completed two bulking periods following propagation) clematis plants were received in 0.9-L containers from a commercial greenhouse on 1 Sept. and were placed in the greenhouse. Plants were provided a cold treatment at $5{ }^{\circ} \mathrm{C}$ for $0,3,6$, or 9 weeks starting 31 Oct. in an unlighted cooler. Then, plants were transplanted to $2.8-\mathrm{L}$ containers and provided a 9- or 16-h photoperiod. Hence, there were eight treatment combinations (four cold duration treatments $\times$ two photoperiods) with 10 replicate plants per treatment. The experimental setup was created with a polyvinyl chloride frame covered with a blackout cloth daily from 1700 to 0800 $\mathrm{HR}$, with ambient light received from 0800 to 1700 HR during both photoperiodic treatments. Within the blackout cloth area, two separate zones provided ambient light for the 9-h photoperiod treatment, whereas two zones contained incandescent bulbs that provided daylength extension lighting (2 $\mu \mathrm{mol} \cdot \mathrm{m}^{-2} \cdot \mathrm{s}^{-1}$ PPFD) from 1645 to $0000 \mathrm{HR}$ to create a $16-\mathrm{h}$ photoperiod. Data were collected during flowering and included the number of shoots per plant, number of open flowers, and the date of the first open flower on each shoot.

Expt. 2: Influence of the temperature of the forcing environment on growth and flowering. Thirty 24-month-old plants that completed two bulking periods and received 9 weeks of cold $\left(5^{\circ} \mathrm{C}\right)$ were transplanted to 2.8-L containers and placed in the greenhouse. Shoots were cut back to the soil line without leaving any visible nodes to promote shoot emergence from underground crown buds on 22 May. Note that if the shoots were cut back to leave aboveground, axillary nodes, then both axillary and underground buds could emerge, leading to a lack of uniformity. Plants were moved to climatecontrolled growth rooms set at a constant temperature of either 21 or $27^{\circ} \mathrm{C}$ and a 16 -h photoperiod using $1000-\mathrm{W}$ metal halide lamps delivering $50 \pm 15 \mu \mathrm{mol} \cdot \mathrm{m}^{-2} \cdot \mathrm{s}^{-1} P P F D$ at the top of the canopy. Fifteen plants per treatment were used. Shoot length, number of nodes, days to first flower, and flower size were recorded for each shoot from the plants in each growing environment. Data collection was finished when $\approx 90 \%$ of the shoots had at least one open flower: 22 July for the $27{ }^{\circ} \mathrm{C}$ treatment and $7 \mathrm{Aug}$. for the $21^{\circ} \mathrm{C}$ treatment.

Expt. 3: Effects of plant growth regulators on shoot formation during first bulking. Single-node stem cuttings of clematis were placed under mist propagation on 25 Nov. for 8 weeks, and then 24 rooted cuttings were transplanted to $2.8-\mathrm{L}$ containers and grown under the natural progression of the photoperiod experienced from November through to May (range, $9 \mathrm{~h} 50 \mathrm{~min}$ to $10 \mathrm{~h}$ ); this progression subsequently increased to $14 \mathrm{~h}$ by May. Ethephon (3.9\% 2-chloroethyl phosphonic acid; Florel; Lawn and Garden Products, Inc. Fresno, CA) at 500 or $1000 \mathrm{mg} \cdot \mathrm{L}^{-1}$, benzylaminopurine (Configure; Fine Americas, Inc., Walnut Creek, CA) at $500 \mathrm{mg} \cdot \mathrm{L}^{-1}$, or deionized water (control) were applied as repeat foliar sprays to plants at $4,6,21$, and 23 weeks after transplanting. A nonionic surfactant (CapSil; Aquatrols, Paulsboro, NJ) was added to each spray solution at a concentration of $0.4 \mathrm{~mL} \cdot \mathrm{L}^{-1}$ to improve solution contact with the leaves. Six replicates were used for each treatment, and the foliar sprays were applied between 0800 and 1100 $\mathrm{HR}$ at a rate of $\approx 34 \mathrm{~mL}$ per plant. After the new leaf development on the primary shoots occurred following propagation cessation, plants were exposed to an 8-week cold treatment at $5{ }^{\circ} \mathrm{C}$ beginning 1 week after the last plant growth regulator application (22 May). Before the application of cold, no differences in shoot numbers (two shoots per plant) were observed between treatments. After the application of cold, shoots were trimmed, leaving two nodes/shoot, and plants were forced in a heated greenhouse under a 16 -h photoperiod (31 July). There were six plant replicates for each treatment. Data collected were number of shoots, number of flowers per shoot, shoot length, the date of flowering, and flower diameter for the first open flower on each shoot.
Table 1. Summary of treatments applied during each phase of Expt. 4.

\begin{tabular}{lcl}
\hline Phase & Weeks & \multicolumn{1}{c}{ Treatments } \\
\hline Propagation & $1-8$ & None \\
Bulking & $9-23$ & Ethephon \\
Precold & $24-33$ & Ethephon, photoperiod \\
Cold & $34-41$ & None \\
Forcing & $42-54$ & None \\
\hline
\end{tabular}

Expt. 4: Effects of ethephon and photoperiod on shoot growth and flowering. This yearlong experiment consisted of five phases that are summarized in Table 1. Single-node stem cuttings were propagated at week 1 (25 Mar.); 8 weeks later (week 8), 48 rooted cuttings were transplanted to $2.8-\mathrm{L}$ containers and grown in a greenhouse under a 16-h photoperiod as previously described. During the first bulking period, three ethephon concentrations $\left(0,500\right.$, or $\left.1000 \mathrm{mg} \cdot \mathrm{L}^{-1}\right)$ were applied during four alternating weeks (weeks 14, 16, 18 , and 20).

During the precold treatment (weeks 24 33 ), four additional applications of 0,500 , or $1000 \mathrm{mg} \cdot \mathrm{L}^{-1}$ ethephon were applied at weeks $26,28,30$, and 32 . The same plants received the same ethephon treatments during bulking as those during the precold phase; therefore, plants received eight ethephon applications from the time of transplant (week 8, 15 May) through the end of the precold period (week 34,13 Nov.). At the start of the precold phase (week 24), plants from each ethephon treatment were divided between two photoperiod treatments ( 9 or $16 \mathrm{~h}$ ). Following an 8 -week, $5{ }^{\circ} \mathrm{C}$ cold period (weeks 34-41), plants were moved to the greenhouse for forcing under a 16-h photoperiod for 13 weeks (weeks 42 53).

Eight plant replicates were used for each of the six treatment combinations (three ethephon concentrations $\times$ two photoperiods). Long days (16 h) and supplemental lighting were provided from 1700 to $0000 \mathrm{HR}$ with metal halide lamps when $P P F D$ measured outside was $<387 \mu \mathrm{mol} \cdot \mathrm{m}^{-2} \cdot \mathrm{s}^{-1}$. Short-day conditions $(9 \mathrm{~h})$ were provided through the use of retractable blackout curtains that were closed from 1700 to $0800 \mathrm{HR}$.

The date of first open flower was collected during the forcing period. Final data collection was performed at the end of the forcing period (week 53). Data collection included the number of shoots, number of flowers per shoot, shoot length, date of flowering, and flower diameter for the first open flower on each shoot.

Data analysis. All data were analyzed using an analysis of variance in JMP 11 (SAS Institute, Inc., Cary, NC). Mean comparisons were conducted using Student's t test during Expt. 2 and Tukey's honestly significant difference test during Expt. 3. Expts. 1 and 4 were analyzed as a split-plot design with ethephon treatments split within photoperiod treatments. For Expt. 1, the main effects were the cold treatment duration and photoperiod. For Expt. 4, the main effects were the photoperiod and concentration of ethephon application. 
Table 2. Analysis of variance for parameters related to the growth and flowering of Clematis $\times$ hybrida 'H.F. Young' provided cold treatment at $5{ }^{\circ} \mathrm{C}$ for $0,3,6$, or 9 weeks followed by a $9-$ or $16-\mathrm{h}$ photoperiod environment (Expt. 1). Data are presented in Fig. 1.

\begin{tabular}{lccc}
\hline Parameter & Duration of cold & Photoperiod & Duration of cold $\times$ photoperiod \\
\hline Shoot number per plant & $* * *$ & $* * *$ & NS \\
Flower number per plant & $* * *$ & $* * *$ & $*$ \\
Time to flower & $* * *$ & $* * *$ & $* * *$ \\
\hline
\end{tabular}

NS, $* * *, * * *$ Nonsignificant or significant at $P \leq 0.05,0.01$, or 0.001 , respectively.

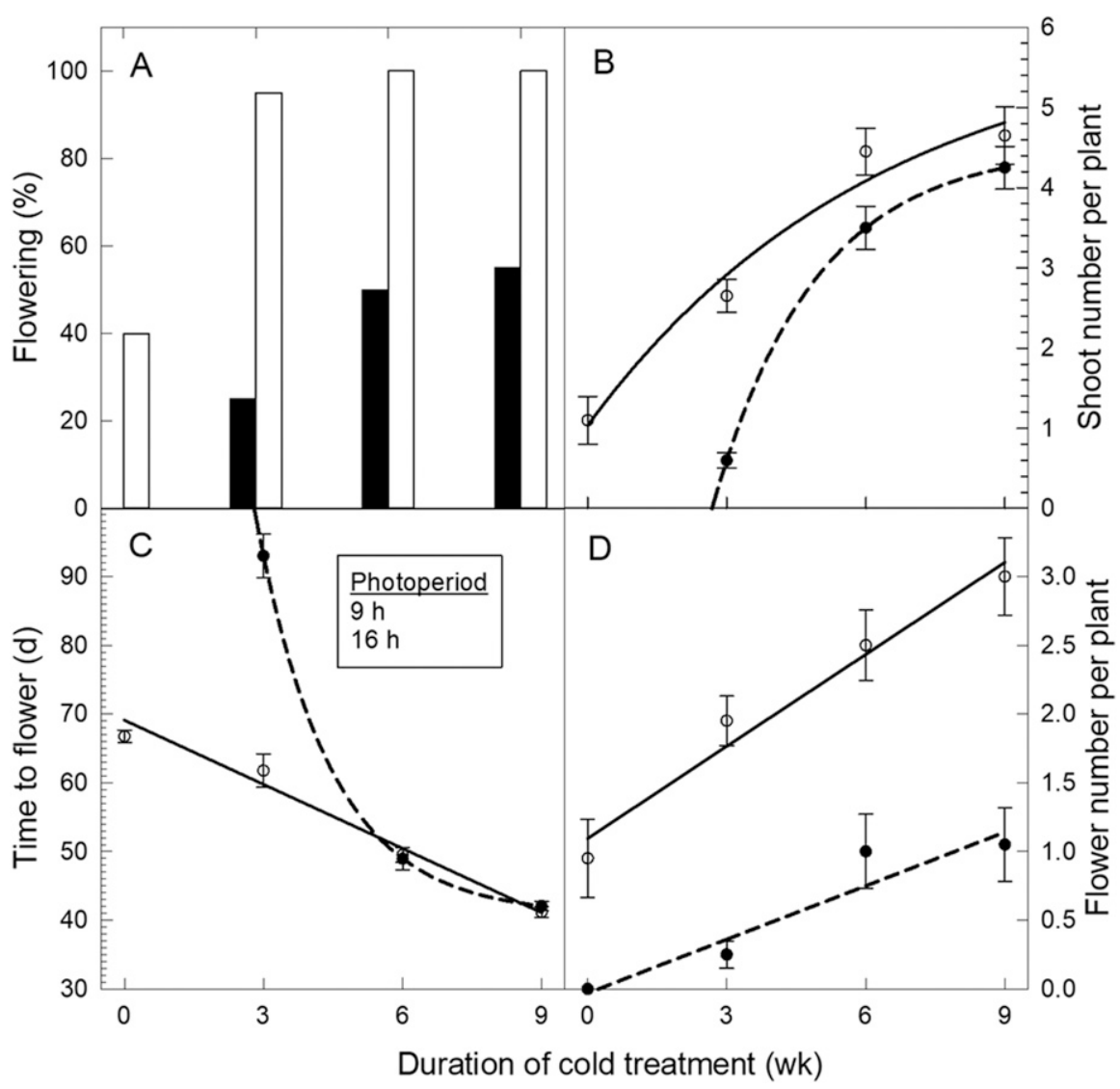

Fig. 1. Percentage of plants flowering, shoot number, time to flower, and flower number of Clematis $\times$ hybrida 'H.F. Young' plants when provided cold treatment at $5{ }^{\circ} \mathrm{C}$ for $0,3,6$, or 9 weeks followed by a 9-h or 16-h photoperiod (Expt. $1 ; \mathrm{n}=10$ ). Analysis of variance results are presented in Table 2. Vertical bars represent \pm 1 SE.

\section{Results}

Expt. 1. Plants grown without a cold treatment followed by a 9 -h photoperiod did not flower; however, $100 \%$ of the plants that received 6 or 9 weeks of cold followed by a 16-h photoperiod did flower (Fig. 1A, Table 2). Only $50 \%$ of the plants flowered in treatments that received 6 or 9 weeks of cold followed by a 9 -h photoperiod. Similarly, the photoperiod and duration of cold interacted to affect time to flower (Fig. 1C) $(P<$ $0.0001)$. For example, time to flower decreased from $67 \pm 1$ to $41 \pm 1 \mathrm{~d}$ as the cold duration increased from 0 to 9 weeks under the 16-h photoperiod, whereas time to flower decreased from $93 \pm 3$ to $49 \pm 2$ as the cold duration increased from 3 to 6 weeks under the 9-h photoperiod. There were no differences in time to flower with the 9- and 16-h photoperiods after receiving 6 or 9 weeks of cold treatment. The number of shoots emerg- ing after the cold treatment increased with the increased duration of cold treatment $(P<$ $0.0001)$ and increased daylength (Fig. 1B) $(P<0.0001)$. Within the 16 -h photoperiod, shoot numbers increased by four as the duration of cold increased from 0 to 9 weeks. Flower number per plant increased as the cold treatment duration increased; this occurred at a faster rate under the 16-h photoperiod than under the 9-h photoperiod (Fig. 1D) $(P<0.01)$. The interaction of photoperiod $\times$ cold treatment was also significant for node number $(P<0.01)$.

Expt. 2. Greater shoot $(P<0.001)$ and flower numbers $(P<0.01)$ were produced at $21^{\circ} \mathrm{C}$ compared to $27^{\circ} \mathrm{C}$ (Table 3 ). However, the average days to flower was $10 \mathrm{~d}$ earlier at $27^{\circ} \mathrm{C}$; plants grown at $21^{\circ} \mathrm{C}$ required $62 \pm 1 \mathrm{~d}$ compared to $52 \pm 1 \mathrm{~d}$ under $27{ }^{\circ} \mathrm{C}(P<$ 0.0001 ). At $27^{\circ} \mathrm{C}$, shoots were $22 \mathrm{~cm}$ longer and had 4 more nodes compared to the $21^{\circ} \mathrm{C}$ treatment $(P<0.001)$.
Expt. 3. Before the application of cold, there were no differences in shoot numbers (two shoots per plant on average; data not shown) between treatments following plant growth regulator application. However, following the application of cold, ethephontreated $\left(500 \mathrm{mg} \cdot \mathrm{L}^{-1}\right)$ plants had $75 \%$ more shoots than the control (Fig. 2) $(P<0.001)$. Benzylaminopurine $\left(500 \mathrm{mg} \cdot \mathrm{L}^{-1}\right)$ did not affect the shoot number. There were no differences among treatments in the number of flowers per shoot $(1.1 \pm 1.5)$, shoot length $(45.7 \pm 14.5 \mathrm{~cm})$, number of nodes $(8.2 \pm$ $1.9)$, average flower size $(12.6 \pm 1.8 \mathrm{~cm})$, or time to flower $(43 \pm 6 \mathrm{~d})$. With an average of one flower per shoot and seven shoots per plant, the $500-\mathrm{mg} \cdot \mathrm{L}^{-1}$ ethephon treatment averaged seven flowers per plant.

Expt. 4. The shoot number developing following the cold treatment was influenced by the ethephon and $(P<0.0001)$ photoperiod treatments $(P<0.05)$ provided before the cold treatment (Table 4). The shoot number increased from $5.3 \pm 0.5$ to $10.6 \pm$ 1.4 shoots per plant as ethephon increased from 0 to $1000 \mathrm{mg} \cdot \mathrm{L}^{-1}$ during the 16 -h photoperiod, whereas the shoot number increased from $3.3 \pm 0.3$ to $8.3 \pm 1.1$ shoots per plant as ethephon increased from 0 to $1000 \mathrm{mg} \cdot \mathrm{L}^{-1}$ during the 9-h photoperiod (Table 4, Fig. 3A). The shoot length was unaffected by the precold treatments. Plants grown during the 16-h photoperiod averaged $8.5 \pm 0.9$ flowers per plant, whereas the plants grown during the 9 -h photoperiod averaged $5.5 \pm 0.9$ flowers per plant across all ethephon treatments $(P<0.05)$. The $1000-\mathrm{mg} \cdot \mathrm{L}^{-1}$ ethephon treatment increased time to flower by $16 \mathrm{~d}$ compared to the control (Fig. 3B) $(P<$ $0.0001)$. The average flower size was $10.6 \pm$ $0.8 \mathrm{~cm}$ among treatments and was unaffected by ethephon and photoperiod treatments. The average shoot length was $66 \pm 15 \mathrm{~cm}$ and was unaffected by the treatments.

\section{Discussion}

Either cold treatment or a 16-h photoperiod can cause flowering in clematis 'H.F. Young', but cold for 6 weeks followed by a 16-h photoperiod during forcing was required for $100 \%$ of the plants to flower. Phlox paniculata similarly requires vernalization followed by a long photoperiod (Runkle et al., 1998). Depending on the species, vernalization can be quantitative, (i.e., plants remain vegetative without cold exposure) or qualitative (i.e., cold hastens flower induction and initiation) (Iversen and Weiler, 1994). Clematis plants without cold treatment and a 9-h photoperiod did not flower, but $40 \%$ of plants flowered within the 16-h photoperiod; therefore, the vernalization requirement can be considered quantitative for clematis. Even when plants received 3 weeks of cold treatment, $95 \%$ of plants flowered under the $16-\mathrm{h}$ photoperiod. Therefore, long photoperiods can partially compensate for a lack of vernalization in clematis 'H.F. Young'. Longday photoperiod responses have been reported to promote flowering in numerous other 
Table 3. Responses of Clematis $\times$ hybrida 'H.F. Young' plants grown under two temperatures $\left(21\right.$ or $\left.27^{\circ} \mathrm{C}\right)$ in the forcing environment following 8 -week, $5{ }^{\circ} \mathrm{C}$ cold treatment (Expt. $2 ; \mathrm{n}=15$ ).

\begin{tabular}{lcc}
\hline & \multicolumn{2}{c}{ Temperature in the forcing environment } \\
\hline Parameter & $21^{\circ} \mathrm{C}$ & $27^{\circ} \mathrm{C}$ \\
Shoot number per plant & $6.7 \pm 0.5 \mathrm{a}$ & $4.7 \pm 0.5 \mathrm{~b}$ \\
Time to flower (d) & $62 \pm 1 \mathrm{a}$ & $52 \pm 1 \mathrm{~b}$ \\
Flower number per plant & $4.7 \pm 0.6 \mathrm{a}$ & $1.9 \pm 0.6 \mathrm{~b}$ \\
Shoot length (cm) & $89 \pm 3 \mathrm{~b}$ & $111 \pm 3 \mathrm{a}$ \\
Node number per stem & $10.8 \pm 0.5 \mathrm{~b}$ & $14.8 \pm 0.5 \mathrm{a}$ \\
\hline
\end{tabular}

Mean separation comparison within rows according to Student's $t$ test at $P \leq 0.05$.

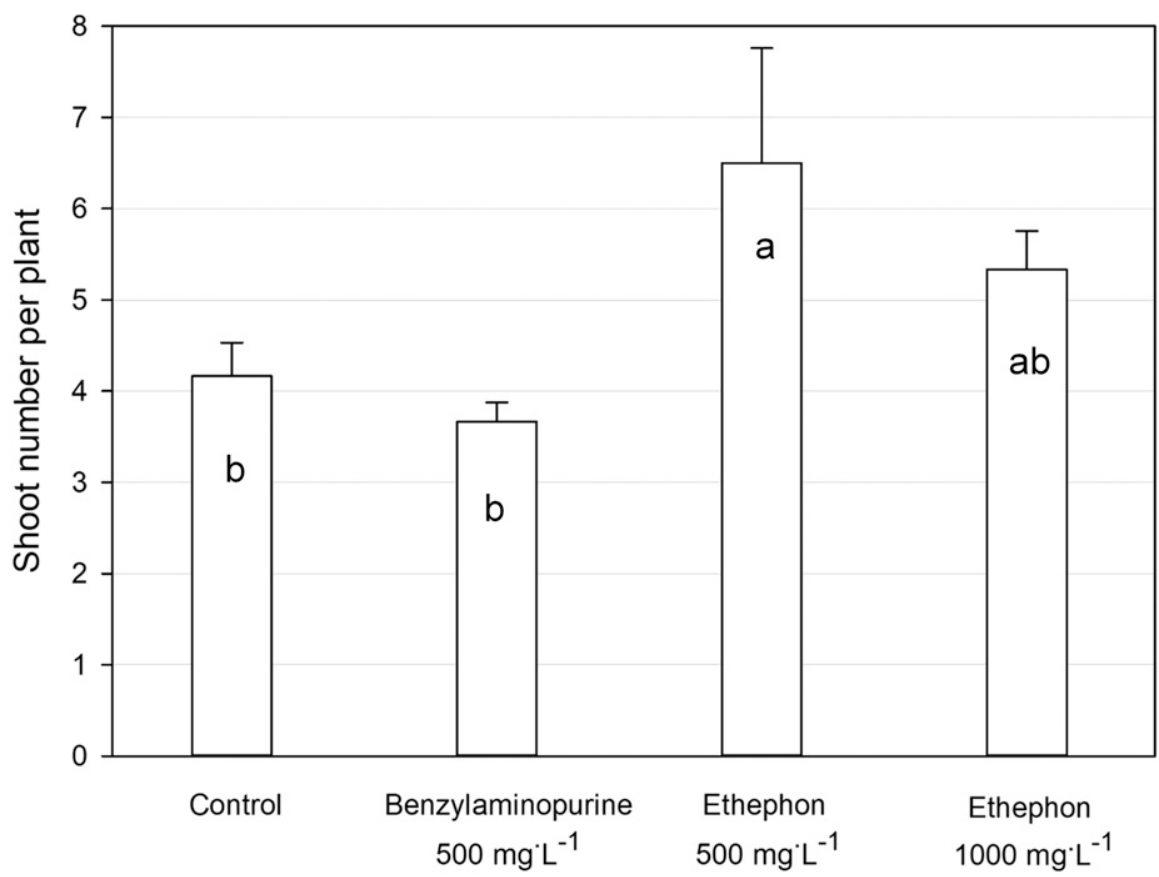

Fig. 2. Number of shoots that Clematis $\times$ hybrida 'H.F. Young' plants developed after an 8 -week, $5{ }^{\circ} \mathrm{C}$ cold treatment when plant growth regulators were applied during the bulking period (before cold treatment) (Expt. 3; $\mathrm{n}=6$ ). Vertical bars represent \pm 1 SE. Mean separation by Tukey's honestly significant difference test at $P \leq 0.05$.

Table 4. Analysis of variance for the effects of ethephon and the photoperiod provided before cold treatment on plant growth and flowering responses measured after the plants completed an 8-week, $5{ }^{\circ} \mathrm{C}$ cold treatment and forced in a greenhouse (Expt. 4).

\begin{tabular}{lccc}
\hline Response & Ethephon & Photoperiod & Ethephon $\times$ photoperiod \\
\hline Shoot number & $* * *$ & $*$ & NS \\
Shoot length & NS & NS & NS \\
Flower number & NS & $* *$ & NS \\
Flower diameter & NS & NS & NS \\
Days to flower & $* * *$ & NS & NS \\
\hline
\end{tabular}

Ns, *, **,***Nonsignificant or significant at $P=0.05,0.01$, or 0.001 , respectively.

herbaceous perennials (Armitage and Garner, 1999; Heide, 2001; Iversen and Weiler, 1994). For Lilium longiflorum, long-day photoperiods can partially compensate for the cold treatment (Dole and Wilkins, 1994).

As evident in Expt. 1, a greater number of shoots per plant occurred with the increasing duration of cold from 0 to 9 weeks. A similar response was observed for hybrid gentian: shoot emergence increased in response to the increased duration of cold from 0 to $42 \mathrm{~d}$ at $5{ }^{\circ} \mathrm{C}$ (Samarakoon et al., 2016). For most temperate climate species, the main factor governing the breakage of dormancy in buds is exposure to low temperatures to satisfy chilling requirements (Lang et al., 1987).
Therefore, in addition to vernalization, exposure to cold temperatures may also break bud dormancy in clematis, leading to increased shoot numbers. From these data, we concluded that cold treatment applied to clematis causes vernalization and may also break dormancy of buds, thus increasing shoot emergence and promoting flowering.

The flower number per plant increased and time to flower decreased as both the cold treatment duration and photoperiod increased (Expt. 1). A reduced duration to harvest maturity following exposure to cold treatment was also noted for other herbaceous perennials, such as gentian hybrids (Samarakoon et al., 2016), Helleborus sp. (Christiaens et al., 2012), and Lavandula angustifolia (Whitman et al., 1996). In clematis, if the cold treatment was received for 6 weeks, then the flowering time was reduced irrespective of the photoperiod during the growing environment, and the response can be considered saturated. Exposure to chilling can reduce the heat units required to reach developmental stages (Huang et al., 1999); therefore, increased durations of cold treatment can lead to faster subsequent shoot development and reduced time to flower. When our results are applied to commercial growing environments, the provision of a minimum of 6 weeks of cold treatment (1008 chilling hours) and forcing under long days can increase flowering and shoot formation of clematis. Because the duration to harvest maturity was reduced, the production time can be shortened. Flower number can be further improved by increasing the duration of cold to 9 weeks. As noted during the current study (Expt. 1) and for other plant species (Harvey and Nowierski, 1988; Ku et al., 2007; Samarakoon et al., 2016), the inadequate accumulation of chilling can result in delayed budbreak, decreased percentages of buds forming shoots, and slow or weakened shoot growth. For commercial application purposed, it will be important to quantify the chilling requirement and the corresponding plant responses of other cultivars of clematis because varieties may respond differently, as also noted for other plant species (Gariglio et al., 2006). For clematis, however, a lack of chilling can be partially compensated by long-day photoperiods (Expt. 1), allowing greenhouse growers to shorten the cold treatment and force plants earlier in the season.

A moderate temperature $\left(21^{\circ} \mathrm{C}\right)$ in the forcing environment resulted in increased shoot and flower numbers (Expt. 2). A reduction of the flower number at warmer temperatures $\left(29.8{ }^{\circ} \mathrm{C}\right)$ was also reported for $O$. fruiticosa (Clough et al., 2001). In the current study, warmer temperatures $\left(27^{\circ} \mathrm{C}\right)$ resulted in increased node numbers and shoot lengths. For Gentiana spp., forcing plants in protected environments under warmer temperatures caused increased shoot lengths compared to outdoor forcing (Samarakoon et al., 2012). For Vitis vinifera, increased temperatures during spring caused greater shoot lengths than plants grown in cooler temperatures (Keller and Tarara, 2010). For clematis, reduced shoot lengths at $21^{\circ} \mathrm{C}$ are an advantage for growers because clematis vines require training; therefore, shorter stems with more flowers produced at $21^{\circ} \mathrm{C}$ will result in better display quality during retail sales compared to warmer forcing temperatures. Growing at moderate temperatures in early spring can provide energy savings. Therefore, growing at $21{ }^{\circ} \mathrm{C}$ can be beneficial in several ways, although time to flower does increase by $10 \mathrm{~d}$.

Lack of branching on 1-year-old plants was noted as a reason for the need to produce clematis on a 2-year schedule. As evident in this study, shoot numbers increased following the first dormancy phase when plants were grown under long days for 26 weeks 


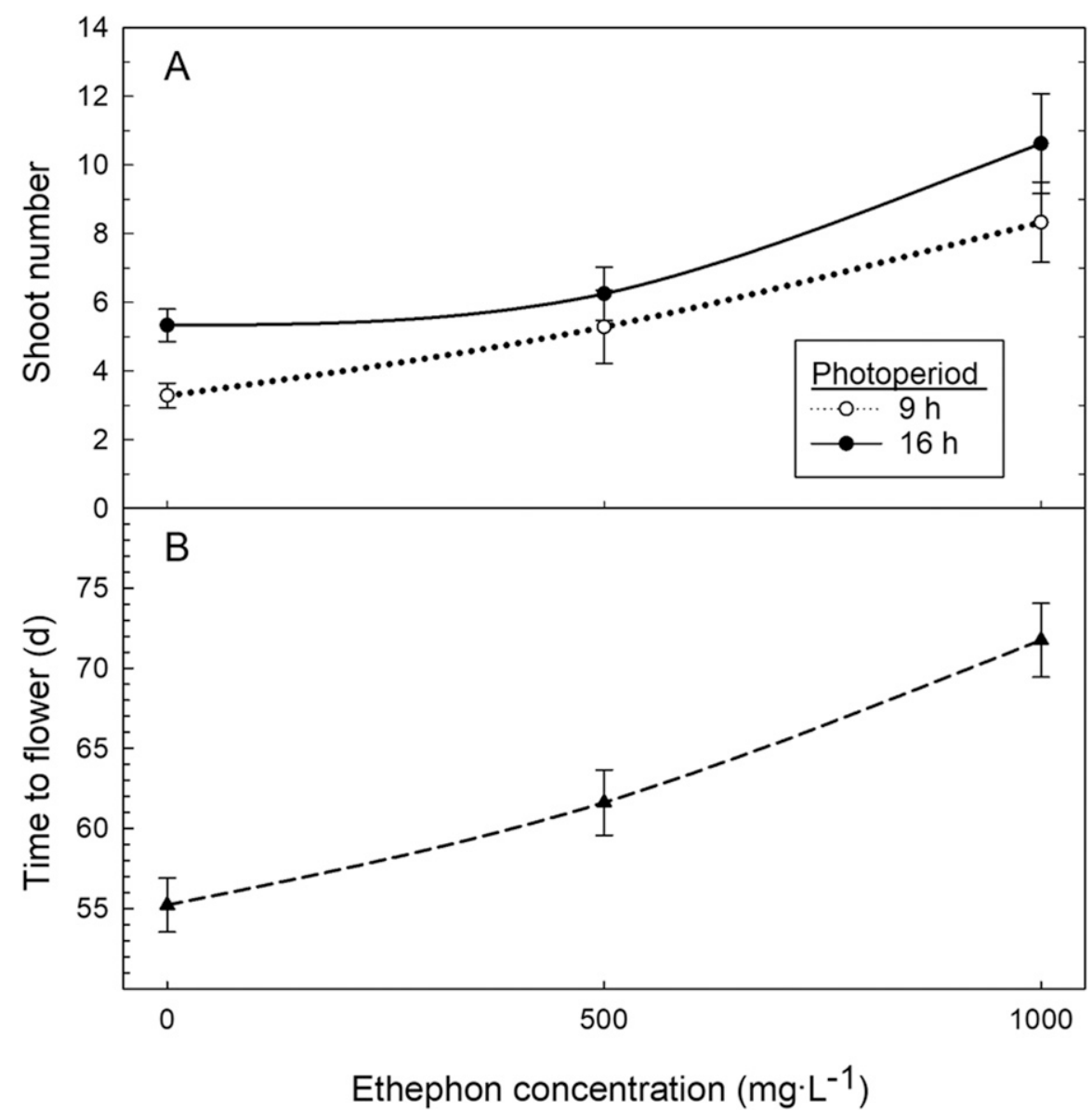

Fig. 3. Number of shoots developed and time to flower for Clematis $\times$ hybrida 'H.F. Young' plants forced in a greenhouse following an 8 -week, $5^{\circ} \mathrm{C}$ cold treatment when the ethephon $\left(0,500\right.$, or $\left.1000 \mathrm{mg} \cdot \mathrm{L}^{-1}\right)$ and photoperiod $(9$ or $16 \mathrm{~h})$ treatments were provided before the cold treatment (Expt. $4 ; \mathrm{n}=8$ ). The photoperiod had no effect on time to flower; therefore, the data were averaged across the two photoperiod treatments. Vertical bars represent \pm 1 SE.

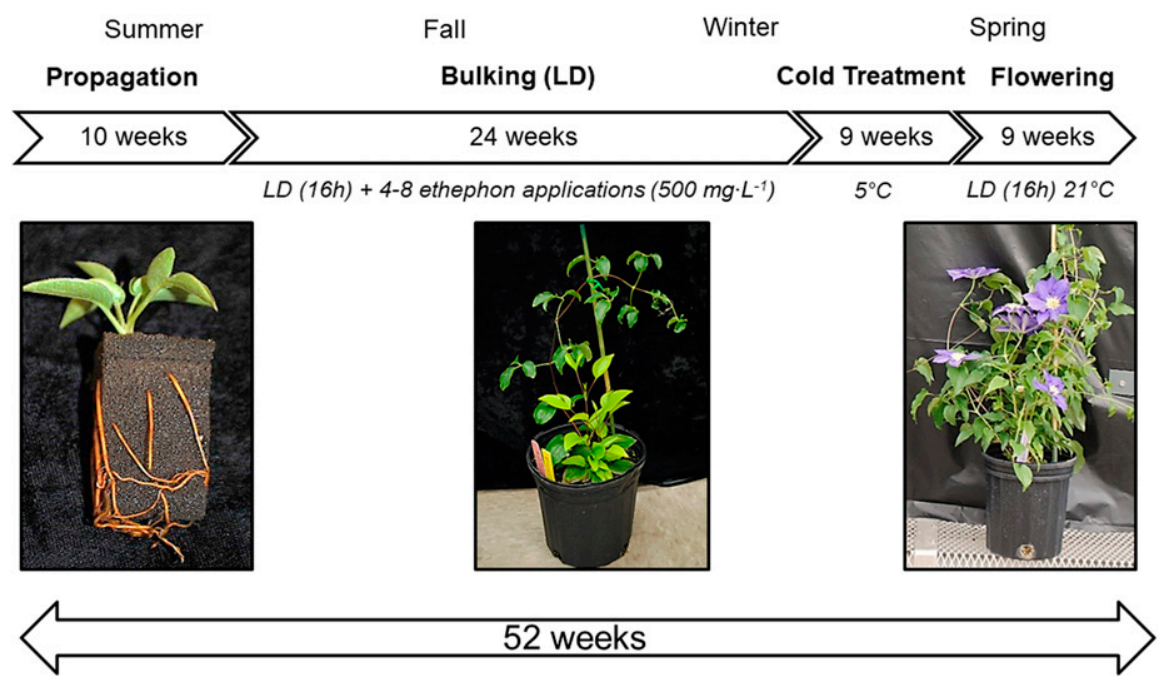

Fig. 4. Proposed 1-year production schedule for clematis 'H.F. Young' including the recommended practices during bulking, cold treatment, and greenhouse forcing.

during the bulking and precold periods (Expt. 4). For some species, such as Sedum telephium and Gentiana spp., naturally occurring short days before a dormancy period increased the number of buds and shoots emerging following cold treatment (Heide, 2001; Samarakoon et al., 2015). However, during our experiment, plants exposed to long-day photoperiods throughout the period before the cold treatment produced more shoots following cold treatment (Expt. 4). Along with the supplemental lighting received, the accumulation of resources in the plants could be higher under long days, thus contributing to the increased growth and development of shoots following the cold treatment. The lack of short days before the cold period may not cause physiological problems because the cold treatment was provided in a cooler at $5{ }^{\circ} \mathrm{C}$ continually. If the cold period were in a natural environment with freezing and rapidly fluctuating temperatures, then perhaps short days before cold may be beneficial for the plants by allowing them to enter a dormancy period before exposure to more extreme and potentially damaging temperatures.

Ethephon applied during the bulking phase of clematis production increased the shoot number following the application of cold (Expts. 3 and 4). All ethephon-treated plants developed at least three more shoots during the bulking phase as compared with the control during Expt. 4. The crown of clematis is capable of supporting the development of a greater number of shoots within a 1 -year cycle than is typically observed following the first dormant period for the current 2-year production practice. The increased shoot formation in response to ethephon was also reported to triple the number of buds and shoots under long-day photoperiods for gentian hybrids (Samarakoon et al., 2015).

Ethephon treatments produced plants that experienced delayed flowering and shorter shoot lengths (Expts. 3 and 4). These two attributes of ethephon have been reported for a variety of species (Miller et al., 2012); as a result, ethephon is a commonly used plant growth regulator used for height control and to delay flowering in greenhouse crops (Latimer and Whipker, 2013). Use of ethephon for herbaceous perennials (Hayashi et al., 2001) has been reported during forcing in the greenhouse following the application of cold as compared to the bulking phase during this study (Expts. 3 and 4). It has been reported that ethephon applied during the forcing of clematis provided no improvement in shoot number (Puglisi, 2002). If greater shoot numbers and shorter production timing are desired in clematis, then ethephon application during the bulking period would be beneficial compared to forcing.

Following the application of cold, the $1000-\mathrm{mg} \cdot \mathrm{L}^{-1}$ ethephon treatments produced plants that had excessively high shoot number compared to what is found commercially (Expt. 4). Increased shoot emergence responses to ethephon from perenniating structures have been reported for other species (Pruski et al., 2006; Samarakoon et al., 2015); however, excessive shoot numbers emphasize the potential significance of the dosage and developmental stage at the time of application (Prange et al., 1998). Our data suggest that eight applications of $500 \mathrm{mg} \cdot \mathrm{L}^{-1}$ ethephon during the vegetative bulking period will produce a commercially acceptable clematis crop. 
As evident during Expt. 3, exogenous cytokinin (benzylaminopurine) did not increase shoot numbers of clematis at the rate applied. The inability of exogenous cytokinin (thiadiazuron) to promote the number of shoots has been previously reported for clematis (Puglisi, 2002); however, benzylaminopurine has been reported to successfully promote branching for other herbaceous perennials (Grossman et al., 2012).

Our proposed schedule with recommended practices is presented in Fig. 4. Rooted clematis liners can be propagated from single-node stem cuttings within 8 to 10 weeks in May and June, when many mature shoots are available for cutting. After the rooted cuttings are transplanted, eight applications of $500 \mathrm{mg} \cdot \mathrm{L}^{-1}$ ethephon during the vegetative bulking period should be performed. The bulking period can be 24 to 28 weeks by providing long days with photoperiodic lighting as natural daylengths decline in August and onward. Then, cold treatment can be provided in a cooler at $5{ }^{\circ} \mathrm{C}$. Six weeks of cold is sufficient to provide $100 \%$ flowering; however, increasing the cold period to 9 weeks slightly increased the flower number. Therefore, we recommend providing 8 to 9 weeks of cold (equivalent to 1344-1512 chilling hours in high or low tunnels) to provide a high-quality retail display. Following cold treatment, plants need to be forced in a greenhouse environment with a $16-\mathrm{h}$ photoperiod at moderate $\left(21{ }^{\circ} \mathrm{C}\right)$ temperatures to achieve a marketable plant with flowers within 8 to 9 weeks. Therefore, the complete schedule will result in a marketable, flowering clematis plant within 48 to 56 weeks.

In conclusion, the production cycle of clematis has not traditionally fit the standard production systems for herbaceous perennials because of the relatively long 2-year cycle from propagation to flowering. We identified the key factors affecting shoot formation (branching) and flowering of clematis and proposed a 1-year production cycle that will significantly reduce overhead costs and likely reduce labor and production costs for producing an attractive, vining clematis plant for the spring sales market.

\section{Literature Cited}

Armitage, A.M. and J.M. Garner. 1999. Photoperiod and cooling duration influence growth and flowering of six herbaceous perennials. J. Hort. Sci. Biotechnol. 74:170-174, doi: 10.1080/ 14620316.1999.11511090.

Christiaens, A., E. Dhooghe, D. Pinxteren, and M. Van Labeke. 2012. Flower development and effects of a cold treatment and a supplemental gibberellic acid application on flowering of Helleborus niger and Helleborus Xericsmithii. Scientia Hort. 136:145-151, doi: 10.1016/j.scienta. 2012.01.017.

Clough, E.A., A.C. Cameron, R.D. Heins, and W.H. Carlson. 2001. Growth and development of Oenothera fruticosa is influenced by vernalization duration, photoperiod, forcing temperature, and plant growth regulators. J. Amer. Soc. Hort. Sci. 126:269-274, doi: 10.21273/ JASHS.126.3.269.

Dole, J.M. 2003. Research approaches for determining cold requirements for forcing and flowering of geophytes. HortScience 38:341-346.

Dole, J.M. and H.F. Wilkins. 1994. Interaction of bulb vernalization and shoot photoperiod on 'Nellie White' Easter lily. HortScience 29:143145, doi: 10.21273/HORTSCI.29.3.143.

Gariglio, N., D.E.G. Rossia, M. Mendow, C. Reig, and M. Agusti. 2006. Effect of artificial chilling on the depth of endodormancy and vegetative and flower budbreak of peach and nectarine cultivars using excised shoots. Scientia Hort. 108:371-377, doi: 10.1016/j.scienta.2006.02.015.

Grossman, M., J. Freeborn, H. Scoggins, and J. Latimer. 2012. Benzyladenine increases branching but reduces root growth of herbaceous perennial liners. HortScience 47:1085-1090, doi: 10.21273/HORTSCI.47.8.1085.

Harvey, S.J. and R.M. Nowierski. 1988. Release of postsenescent dormancy in leafy spurge $(E u$ phorbia esula) by chilling. Weed Sci. 36:784786.

Hayashi, T., R.D. Heins, A.C. Cameron, and W.H. Carlson. 2001. Ethephon influences flowering, height, and branching of several herbaceous perennials. Scientia Hort. 91:305-324, doi: 10.1016/S0304-4238(01)00225-4.

Heide, O.M. 2001. Photoperiodic control of dormancy in Sedum telephium and some other herbaceous perennial plants. Physiol. Plant. 113:332-337, doi: 10.1034/j.1399-3054.2001. 1130305.x.

Huang, N., K.A. Funnell, and B.R. MacKay. 1999. Vernalization and growing degree-day requirements for flowering of Thalictrum delavayi 'Hewitt's Double'. HortScience 34:59-61, doi: 10.21273/HORTSCI.34.1.59.

Iversen, R.R. and T.C. Weiler. 1994. Strategies to force flowering of six herbaceous garden perennials. HortTechnology 4:61-65, doi: 10.21273/ HORTTECH.4.1.61.

Keller, M. and J.M. Tarara. 2010. Warm spring temperatures induce persistent season-long changes in shoot development in grapevines. Ann. Bot. 106:131-141, doi: 10.1093/aob/ mcq091.

$\mathrm{Ku}$, Y., D.J. Woolley, A.R. Hughes, and M.A Nichols. 2007. Temperature effects on dormancy, bud break and spear growth in asparagus (Asparagus officinalis L.). J. Hort. Sci. Biotechnol. 82:446-450, doi: 10.1080/14620316. 2007.11512257.

Lang, G.A., J.D. Early, G.C. Martin, and R.L. Darnell. 1987. Endo-, para-, and ecodormancy: Physiological terminology and classification for dormancy research. HortScience 22:371-377.
Latimer, J.G. and B. Whipker. 2013. Selecting and using plant growth regulators on floricultural crops. Virginia Cooperative Extension. $<\mathrm{https}: / /$ vtechworks.lib.vt.edu/bitstream/handle/10919/ 48109/HORT-43P-pdf.pdf>.

Miller, W.B., N.S. Mattson, X. Xie, D. Xu, C.J Currey, K.L. Clemens, R.G. Lopez, M. Olrich, and E.S. Runkle. 2012. Ethephon substrate drenches inhibit stem extension of floriculture crops. HortScience 47:1312-1319, doi: 10.21273/ HORTSCI.47.9.1312.

Prange, R.K., W. Kalt, B.J. Daniels-Lake, C.L. Liew, R.T. Page, J.R. Walsh, P. Dean, and R. Coffin. 1998. Using ethylene as a sprout control agent in stored 'Russet Burbank' potatoes. J. Amer. Soc. Hort. Sci. 123:463-469, doi: 10.21273/JASHS.123.3.463.

Pruski, K., R.K. Prange, B.J. Daniels-Lake, J. Nowak, T. Astatkie, and D.H. Ronis. 2006. Growth-room and field studies with seed tubers treated with ethylene and 1-methylcyclopropene (1-MCP) during storage. Amer. J. Potato Res. 83:149-160.

Puglisi, S.E. 2002. Use of plant growth regulators to enhance branching of Clematis spp. Master of Science, Department of Horticultural Science, Virginia Polytechnic Institute and State University, Blacksburg, VA.

Runkle, E.S., R.D. Heins, A.C. Cameron, and W.H. Carlson. 1998. Flowering of herbaceous perennials under various night interruption and cyclic lighting treatments. HortScience 33:672677, doi: 10.21273/HORTSCI.33.4.672.

Samarakoon, U.C., K.A. Funnell, D.J. Woolley, and E.R. Morgan. 2012. Temperature impacts changes in crown buds and flowering of gentian 'Spotlight'. Scientia Hort. 143:49-55, doi: 10.1016/j.scienta.2012.06.002.

Samarakoon, U.C., K.A. Funnell, D.J. Woolley, and E.R. Morgan. 2015. Influence of photoperiod regime and exogenous plant growth regulators on crown bud formation in gentian. Scientia Hort. 182:56-64, doi: 10.1016/j.scienta. 2014.11.023.

Samarakoon, U.C., D.J. Woolley, E.R. Morgan, and K.A. Funnell. 2016. Ontogeny of crown bud clusters and dormancy-breaking treatments influence productivity and spread of harvest maturity of gentian 'Showtime Diva'. HortScience 51:829-837, doi: 10.21273/HORTSCI.51.7.829.

Shillo, R. and A.H. Halevy. 1981. Flower and corm development in gladiolus as affected by photoperiod. Scientia Hort. 15:187-196, doi: 10.1016/0304-4238(81)90107-2.

Vesk, P.A. and M. Westoby. 2004. Sprouting ability across diverse disturbances and vegetation types worldwide. J. Ecol. 92:310-320.

Whitman, C.M., R.D. Heins, A.C. Cameron, and W.H. Carlson. 1996. Cold treatments, photoperiod, and forcing temperature influence flowering of Lavandula angustifolia. HortScience 31:11501153, doi: 10.21273/HORTSCI.31.7.1150.

Whitman, C.M., R.D. Heins, A.C. Cameron, and W.H. Carlson. 1997. Cold treatment and forcing temperature influence flowering of Campanula carpatica 'Blue Clips'. HortScience 32:861-865, doi: 10.21273/HORTSCI.31.7. 1150 . 